Keywords: oesophageal cancer; fluorodeoxyglucose positron emission tomography-computed tomography; computed tomography; multi-disciplinary team

\title{
Evaluating the role of fluorodeoxyglucose positron emission tomography-computed tomography in multi-disciplinary team recommendations for oesophago-gastric
} cancer

\author{
N S Blencowe ${ }^{\star 1,2}$, R N Whistance ${ }^{1,2}$, S Strong ${ }^{1,2}$, E J Hotton ${ }^{3}$, S Ganesh ${ }^{3}$, H Roach ${ }^{4}$, M Callaway ${ }^{4}$ \\ and J M Blazeby ${ }^{1,2}$
}

${ }^{1}$ Centre for Surgical Research, School of Social and Community Medicine, University of Bristol, Bristol, UK; ${ }^{2}$ Division of Surgery Head and Neck, University Hospitals Bristol NHS Foundation Trust, Bristol, UK; ${ }^{3}$ University of Bristol Medical School, Bristol, UK and ${ }^{4}$ Division of Diagnostics and Therapies, University Hospitals Bristol NHS Foundation Trust, Bristol, UK

Background: National guidelines recommend that fluorodeoxyglucose positron emission tomography-computed tomography (PET-CT) is performed in all patients being considered for radical treatment of oesophageal or oesophago-gastric cancer without computerised tomography scan (CTS) evidence of metastasis. Guidance also mandates that all patients with cancer have treatment decisions made within the context of a multi-disciplinary team (MDT) meeting. Little is known, however, about the influence of PET-CT on decision making within MDTs. The aim of this study was to assess the role of PET-CT in oesophago-gastric cancer on MDT decision making.

Methods: A retrospective analysis of a prospectively held database of all patients with biopsy-proven oesophageal or oesophagogastric cancer discussed by a specialist MDT was interrogated. Patients selected for radical treatment without CTS evidence of M1 disease were identified. The influence of PET-CT on MDT decision making was examined by establishing whether the PET-CT confirmed CTS findings of MO disease (and did not change the patient staging pathway) or whether the PET-CT changed the pathway by showing unsuspected M1 disease, refuting CTS suspicious metastases, or identifying another lesion (needing further investigation).

Results: In 102 MDT meetings, 418 patients were discussed, of whom 240 were initially considered for radical treatment and 238 undergoing PET-CT. The PET-CT confirmed CTS findings for 147 (61.8\%) and changed MDT recommendations in 91 patients (38.2\%) by (i) identifying M1 disease $(n=43)$, (ii) refuting CTS suspicions of M1 disease $(n=25)$, and (iii) identifying new lesions required for investigations $(n=23)$.

Conclusion: The addition of PET-CT to standard staging for oesophageal cancer led to changes in MDT recommendations in 93 (38.2\%) patients, improving patient selection for radical treatment. The validity of the proposed methods for evaluating PET-CT on MDT decision making requires more work in other centres and teams. 
Multi-disciplinary team (MDT) meetings offer an integrated approach to health care in which medical and allied health professionals consider relevant options and collaboratively develop individual treatment recommendations for patients. They are a mandatory forum to discuss all new cancer patients in the UK (Department of Health, 2000) and in recent years have also been adopted in North America (Tripathy, 2003), Australia (Luxford and Rainbird, 2001; Zorbas et al, 2003) and other parts of continental Europe (Valdagni et al, 2005; Van Nes and Van de Velde, 2005). Discussion within the context of a MDT ensures patients benefit from the knowledge and experiences of a variety of specialists and this has resulted in improvements in care such as decreasing the time from diagnosis to treatment (Kingsmore et al, 2004), and greater patient and participant satisfaction (Tripathy, 2003). It is especially important when potential survival benefits must be balanced with the risks conferred by the radical treatment of some cancers, such as oesophago-gastric disease (Avery et al, 2007; Abate et al, 2010). Careful MDT treatment selection and accurate detection of metastatic disease is therefore crucial in the staging pathway to inform treatment plans for these patients.

Over the past decade, fluorodeoxyglucose (FDG) positron emission tomography-computed tomography (PET-CT) has been introduced to improve the staging of oesophago-gastric cancer. PET-CT integrates functional and anatomical imaging to allow precise localisation of areas of high-metabolic activity within a single superimposed picture and may, therefore, detect metastatic disease not identified by standard computerised tomography scanning (CTS) alone. Although UK national radiological guidelines recommend the use of PET-CT for staging oesophageal and oesophago-gastric cancer (The Royal College of Radiologists and the Royal College of Physicians, 2012), Scottish Intercollegiate Guidelines do not currently endorse routine use and recent evidence suggests that uptake varies considerably between centres with rates ranging between 48 and 98\% (National OesophagoGastric Cancer Audit, 2010). Moreover, there is no consensus as to how the impact of PET-CT should be evaluated and reported in clinical research studies (Tunis and Whicher, 2009). To date, different approaches have been used, including correlation with post-operative histology, examination of response to neoadjuvant treatments, and prediction of survival (Salahudeen et al, 2008; Noble et al, 2009; Gillies et al, 2011; Brown et al, 2012; Gillies et al, 2012; Klayton et al, 2012; Shum et al, 2012; Yanagawa et al, 2012; Zhu et al, 2012; Tan et al, 2013). One study reported that PET-CT helped to plan the management of 174 cases (91\%), changed staging in $65(34 \%)$, and changed management in 50 cases (26\%); however, it is unclear how this was assessed (Gillies, 2011).

The aim of this study was to assess the use of PET-CT in MDT decision making and to propose a method for evaluating this role.

\section{MATERIALS AND METHODS}

Patients with oesophageal or oesophago-gastric adenocarcinoma or squamous cell carcinoma were identified from a prospective MDT database. Included were all those considered for radical treatment between June 2008 and June 2010. The MDT, based at University Hospitals Bristol NHS Foundation Trust, receives referrals from Musgrove Park Hospital (Taunton), North Bristol NHS Trust, Royal United Hospital NHS Trust (Bath), Yeovil District Hospital NHS Foundation Trust, and Weston Area Health NHS Trust, serving a resident population of approximately 1.5 million. All radiological, clinical, and pathological patient information are recorded in electronic databases and MDT recommendations are recorded and supplemented with a detailed letter written by the specialist team to the referring hospital to allow timely dissemination of information to the relevant personnel.
Staging pathway. The MDT protocol for management of patients with oesophageal and oesophago-gastric cancer includes review of endoscopic biopsies to confirm the histological diagnosis and review of the chest and abdominal CTS. Patients identified with definitive metastatic disease on CTS, or those unsuitable for radical treatment because of co-morbidities or frailty, are offered palliative treatments including best supportive care. If the CTS does not show metastatic disease or where there is any uncertainty, PET-CT is performed and this is also reviewed at the MDT meeting. A consultant radiologist is always present at the MDT meeting, and full reports of the CT from the referring Trust are also reviewed before the discussion. The database, therefore, contains prospective records of the MDT decisions before and after PET-CT review and details of final treatment recommendations after completion of all investigations including endoscopic ultrasound scan (EUS), laparoscopy, and bronchoscopy when performed (Figure 1).

Data extraction, analyses, and classification of the influence of PET-CT on MDT decision making. Details including age, gender, histological diagnosis, and recommendations recorded at each MDT meeting following CTS, PET-CT, other staging investigations, and the final treatment plan were extracted for each patient.

The number of patients recommended for radical treatment by the MDT was recorded and whether a PET-CT was performed. The influence of PET-CT on the MDT decision making was examined by calculating the proportions of patients in whom the PET-CT did not influence MDT recommendations (i.e., PET-CT confirmed the CT stage of M0 and the staging pathway continued) or PET-CT lead to a change in MDT recommendations (i.e., PETCT showed unsuspected metastatic disease, refuted CTS suspected metastases, or detected another abnormality leading to the need for further investigations; Table 1).

Final treatments received were verified by independent review of pathological databases and hospital notes. Where the MDT-recommended radical treatment and this was not received, reasons for this were documented.

\section{RESULTS}

During the study 418 new patients with oesophageal or oesophagogastric cancer were discussed at 102 MDT meetings, of whom 240 were considered for radical treatment following MDT review of the CTS. Most patients were male and the predominant histological subtype was adenocarcinoma (Table 2).

Of the 240 patients, 238 underwent PET-CT. One patient, selected for endoscopic mucosal resection, was not scanned and the reason for the other missing PET-CT was unclear (Figure 2). In 147 (61.8\%) patients, the PET-CT results did not change MDT recommendations (Figure 2 and Table 3). In 91 (38.2\%), however, PET-CT changed MDT recommendations by:

i Refuting the possibility of widespread disease $(n=25)$

ii Identifying metastatic disease $(n=43)$

iii Identifying lesions that required further investigations $(n=23)$

The distribution of histological tumour types was similar within each group although this was not assessed statistically due to small patient numbers (Table 3). The sites of metastatic disease detected by PET-CT are listed in Table 4. Further investigations included colonoscopy $(n=11)$, excision biopsy $(n=5)$, EUS-guided biopsy $(n=2)$, bronchoscopy $(n=2)$, fine needle aspiration $(n=1)$, magnetic resonance imaging $(n=1)$, and bone marrow aspiration $(n=1)$. Of these, four confirmed M1 disease and patients received palliative treatments. In total, therefore, PET-CT prevented 


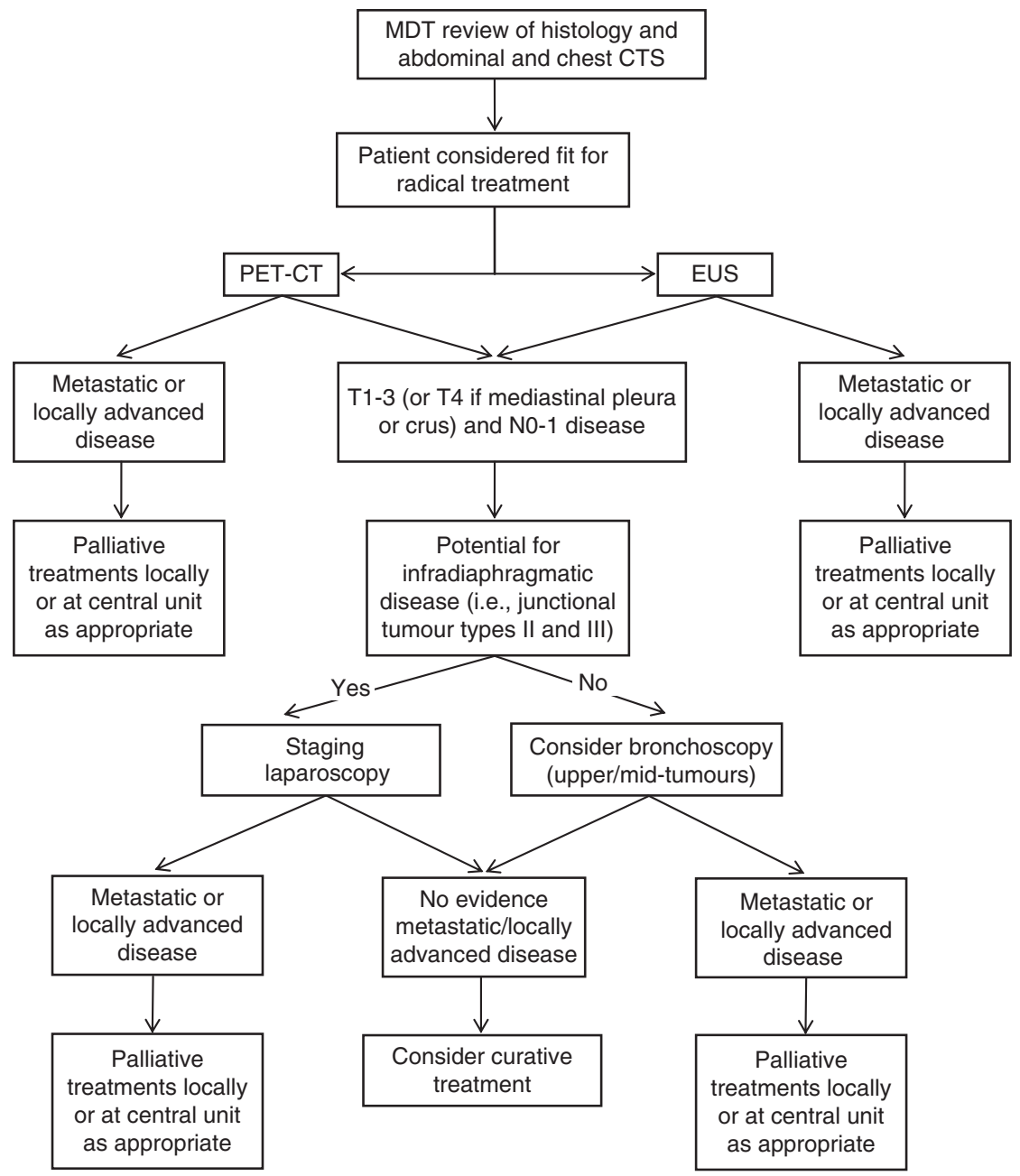

Figure 1. Staging pathway for patients with oesophageal and oesophago-gastric cancer within the Avon, Wiltshire, and Somerset Cancer network.

Table 1. Examples of CTS and PET-CT report findings and categorisation of changes in MDT decision making

\begin{tabular}{|l|l|l|}
\hline Example CTS report & Example PET-CT report & Influence on MDT decision making \\
\hline $\begin{array}{l}\text { Distal oesophageal thickening, extension into } \\
\text { gastroesophageal junction, no mediastinal } \\
\text { involvement, no metastasis }\end{array}$ & $\begin{array}{l}\text { Oesophageal carcinoma, no lymphadenopathy, no distant } \\
\text { metastasis }\end{array}$ & $\begin{array}{l}\text { No change in recommendation: PET-CT } \\
\text { confirmed findings of the CTS }\end{array}$ \\
\hline $\begin{array}{l}\text { Distal oesophageal tumour, small volume } \\
\text { lymphadenopathy in the chest and abdomen of } \\
\text { uncertain significance }\end{array}$ & Single small circumferential distal oesophageal tumour & $\begin{array}{l}\text { Change in recommendation: PET-CT } \\
\text { showed no metastases where the CTS } \\
\text { raised this possibility }\end{array}$ \\
\hline $\begin{array}{l}\text { Junctional tumour, no evidence of } \\
\text { lymphadenopathy or disseminated disease }\end{array}$ & $\begin{array}{l}\text { There are bone metastasis and contiguous nodal disease } \\
\text { at upper oesophagus }\end{array}$ & $\begin{array}{l}\text { Change in recommendation: PET-CT } \\
\text { showed metastases where the CTS did not }\end{array}$ \\
\hline $\begin{array}{l}\text { Gastro-oesophageal junctional tumour with } \\
\text { locoregional lymphadenopathy but no metastatic } \\
\text { disease }\end{array}$ & $\begin{array}{l}\text { Large gastro-oesophageal carcinoma, FDG avid mass } \\
\text { projecting from lower lobe of caecum, which could } \\
\text { represent malignancy }\end{array}$ & $\begin{array}{l}\text { Change in recommendation: PET-CT } \\
\text { prompted additional staging investigations }\end{array}$ \\
\hline Abbreviations: CTS=computerised tomography; FDG = fluorodeoxyglucose; MDT =multi-disciplinary team; PET-CT=positron emission tomography-computed tomography.
\end{tabular}

47 patients (19.7\%) from undergoing radical treatment in the presence of previously undetected metastatic disease.

Of the remaining patients, $143(73.3 \%)$ commenced and 128 $(65.6 \%)$ completed radical treatment (Table 5). Reasons for radical treatment were not started in certain patients included the detection of metastatic disease by other staging modalities $(n=10)$, issues regarding fitness for surgery $(n=22)$, patient choice $(n=4)$, and in six patients the reason could not be determined. Disease progression or toxicity during neoadjuvant treatment precluded 10 patients from completing radical treatment and in a further 6 patients occult metastatic disease was detected at the time of planned surgical resection.

\section{DISCUSSION}

This study examined the influence of PET-CT on MDT decision making in patients with oesophageal and oesophago-gastric cancer, and found that PET-CT influenced management by changing 
treatment pathways from radical to palliative intent in 43 patients (18.1\%), uncertainty to curative intent in $25(10.4 \%)$, and prompting further investigations in 23 patients (9.5\%). Undertaking PET-CT prevented 47 (19.7\%) patients from receiving radical treatment in the presence of undetected metastatic disease, thereby confirming the importance of incorporating this investigation into the routine staging pathway for oesophago-gastric cancer. It is therefore concluded that PET-CT is a valuable adjunct to decision making in oesophageal and oesophago-gastric cancer.

\begin{tabular}{|c|c|}
\hline & All patients $(n=240)$ \\
\hline $\begin{array}{l}\text { Mean age at diagnosis (s.d.), years } \\
\text { Male (\%) }\end{array}$ & $\begin{array}{c}65.0(9.4) \\
179(74.6)\end{array}$ \\
\hline \multicolumn{2}{|l|}{ Histological tumour type (\%) } \\
\hline $\begin{array}{l}\text { Adenocarcinoma } \\
\text { Squamous cell carcinoma } \\
\text { Other cell type } \\
\text { Unknown }\end{array}$ & $\begin{aligned} 169 & (70.4) \\
66 & (27.5) \\
1 & (0.4) \\
4 & (1.7)\end{aligned}$ \\
\hline \multicolumn{2}{|c|}{ Staging investigations performed (\%) } \\
\hline $\begin{array}{l}\text { CTS } \\
\text { PET-CT } \\
\text { EUS } \\
\text { Staging laparoscopy }\end{array}$ & $\begin{array}{l}240(100.0) \\
238(99.2) \\
194(80.8) \\
52(21.7)\end{array}$ \\
\hline Eventual radical treatment (\%) & $139(57.9)$ \\
\hline $\begin{array}{l}\text { Oesophagectomy } \\
\text { Gastrectomy } \\
\text { Definitive chemoradiotherapy } \\
\text { Other }\end{array}$ & $\begin{array}{l}84(60.4) \\
10(7.2) \\
31(22.3) \\
14(10.1)\end{array}$ \\
\hline \multicolumn{2}{|l|}{ If surgical treatment (\%) } \\
\hline Neoadjuvant chemotherapy & $81(86.2)$ \\
\hline
\end{tabular}

Previous studies of oesophago-gastric cancer patients have used PET-CT to assess response to neoadjuvant treatments (Klayton et al, 2012; Yanagawa et al, 2012; Tan et al, 2013) and investigate how it might predict survival (Brown et al, 2012; Shum et al, 2012; Zhu et al, 2012), but its potential benefits in improving the staging pathway have been less well examined. One study documented PET-CT findings in 191 oesophageal cancer patients discussed at a central MDT, which received referrals from 12 peripheral hospitals (Noble et al, 2009). Results of PET-CT scans were categorised as 'true positives' (PET-CT correctly identifying metastases not detected by CTS or EUS), 'false positives' (PET-CT incorrectly identifying metastases not detected on CTS or EUS), 'true negatives', and 'false negatives'. Neither of the latter two categories was defined in the paper and the process for categorising PET-CT results was only partially reported, meaning that the classification system was difficult to interpret. The authors concluded that PETCT helped to plan the management of 174 cases (91\%), changed staging in $65(34 \%)$ and altered management in 50 cases $(26 \%)$; however, it is unclear what the authors meant by these terms. Information was also provided regarding the specificity (94\%) and sensitivity (91\%) of PET-CT but details of how these figures were calculated were missing. Another study, conducted within a central MDT, included 200 patients and compared PET-CT reports with the results of all other staging investigations (Gillies et al, 2011). Patients were categorised into five groups: 'PET-CT upstaged disease to unresectable', 'PET-CT downstaged disease to potentially resectable', 'PET-CT demonstrated metastatic disease that was subsequently determined by cytology to be benign', 'PET-CT demonstrated potentially resectable disease that was subsequently determined by EUS or laparoscopy to be unresectable', and 'PETCT agreed with combined CTS, EUS, and laparoscopy'. No definitions were provided for the first two categories and it was unclear whether the groups were mutually exclusive. In addition, some groups compared the reports of PET-CT with those of staging investigations that occurred before and after the PET-CT was performed in the staging pathway, meaning that the impact of PET-CT itself was difficult to elicit. Last, although five groups were described within the methods, the results section classified the impact of PET-CT into 12 separate categories making replication of this methodology in this study difficult. A third study compared TNM staging from PET-CT with EUS and CTS results and linked

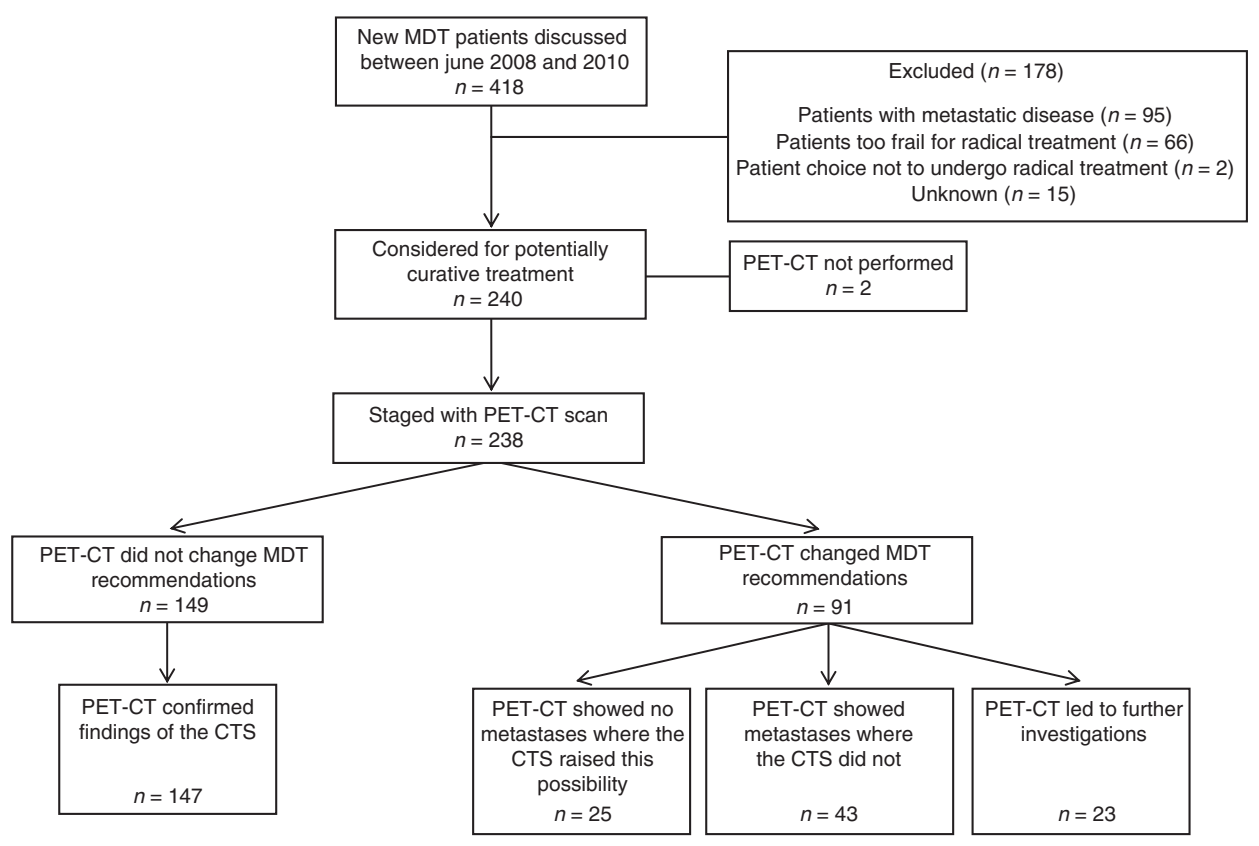

Figure 2. Flow of included patients within the study. 
Table 3. Categorisation of the influence of PET-CT on MDT decision making

\begin{tabular}{|c|c|c|c|}
\hline Category & CTS finding & PET-CT finding & $n=238(\%)$ \\
\hline No change in recommendation: PET-CT confirmed findings of the CTS & Curative disease & Curative disease & $147(61.8)^{a}$ \\
\hline $\begin{array}{l}\text { Change in recommendation: PET-CT showed no metastases where the } \\
\text { CTS raised this possibility }\end{array}$ & $\begin{array}{l}\text { Indeterminate, suspicion of } \\
\text { palliative disease }\end{array}$ & Curative disease & $25(10.5)^{b}$ \\
\hline $\begin{array}{l}\text { Change in recommendation: PET-CT showed metastases where the CTS } \\
\text { did not }\end{array}$ & Curative disease or indeterminate & Palliative disease & $43(18.1)^{c}$ \\
\hline $\begin{array}{l}\text { Change in recommendation: PET-CT prompted additional staging } \\
\text { investigations }\end{array}$ & Curative disease & $\begin{array}{l}\text { 'Hotspot' distant from the } \\
\text { primary tumour }\end{array}$ & $23(9.7)^{d}$ \\
\hline \multicolumn{4}{|c|}{$\begin{array}{l}\text { Abbreviations: } \mathrm{CTS}=\text { computerised tomography; } \mathrm{PET}-\mathrm{CT}=\text { positron emission tomography-computed tomography; } \mathrm{SCC}=\text { squamous cell carcinoma. Histological cell types within each group. } \\
\text { a Adenocarcinoma }=106, \mathrm{SCC}=40 \text {, unknown }=1 . \\
{ }^{\mathrm{b}} \text { Adenocarcinoma }=16, \mathrm{SCC}=7, \text { unknown }=2 . \\
{ }^{\mathrm{c} A d e n o c a r c i n o m a}=29, \mathrm{SCC}=13, \text { unknown }=1 . \\
{ }^{\mathrm{d}} \text { Adenocarcinoma }=17, \mathrm{SCC}=6 .\end{array}$} \\
\hline
\end{tabular}

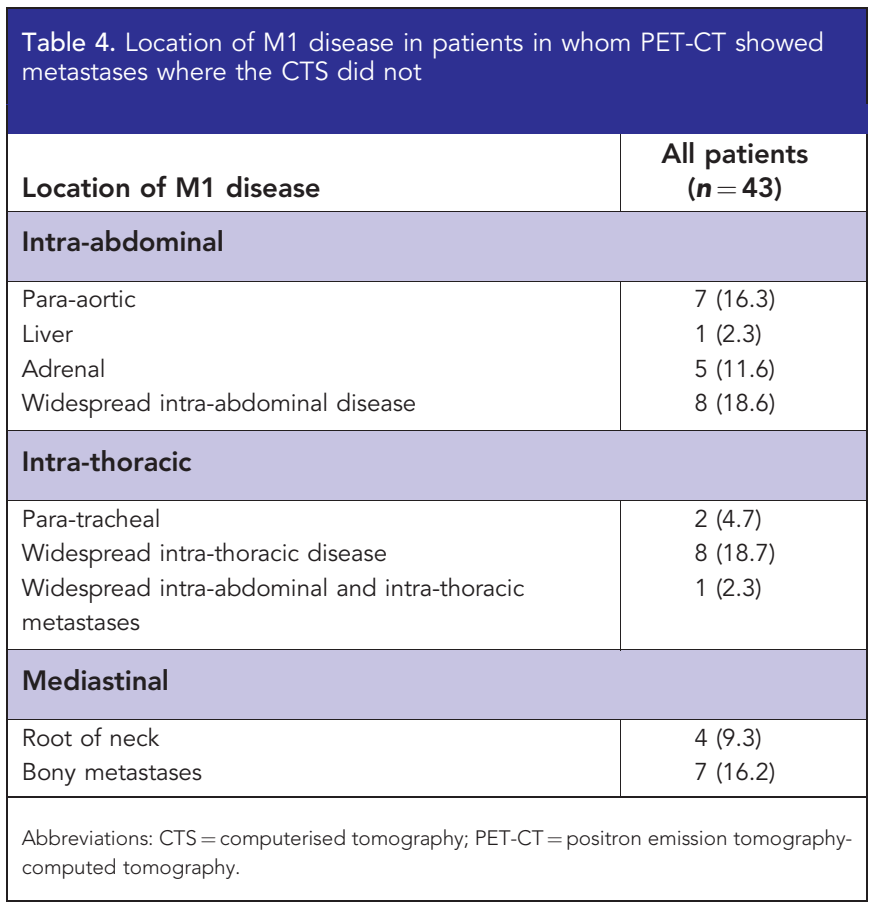

this to post-operative histological reports (Salahudeen et al, 2008). However, only 25 patients were included meaning that the number of patients in each category was small. This classification system is also difficult to apply to diseases where neoadjuvant chemotherapy is used because of the impact of this on post-operative histology. These individual aspects of staging are perhaps less important because the main question being asked of PET-CT is whether the patient should undergo radical or palliative treatment, which was not addressed in these articles, and neither was the impact of PET$\mathrm{CT}$ on treatment recommendations within the MDT.

Although it is thought that this is the first study to comprehensively categorise how PET-CT influences MDT decision making for patients with oesophageal cancer, it has some limitations. Although it was conducted in the context of a central meeting consisting of six referring hospitals, it was limited to a single MDT and it is possible that results are not widely generalisable; however, this MDT follows standard guidelines for oesophageal cancer treatment and staging (Allum et al, 2011). Second, although decision making was recorded prospectively, data were extracted retrospectively and therefore relied on accuracy of record keeping. It was not possible to calculate survival differences

\begin{tabular}{|c|c|c|c|}
\hline & $\begin{array}{c}\text { PET-CT } \\
\text { confirming } \\
\text { CTS findings } \\
\text { of M0 } \\
\text { disease } \\
\mathbf{n}=147(\%)\end{array}$ & $\begin{array}{c}\text { PET-CT } \\
\text { refutes CT } \\
\text { evidence of } \\
\text { possible } \\
\text { metastases } \\
n=25(\%)\end{array}$ & $\begin{array}{c}\text { PET-CT } \\
\text { recommends } \\
\text { additional } \\
\text { staging } \\
\text { investigations } \\
n=23(\%)\end{array}$ \\
\hline $\begin{array}{l}\text { Radical treatment } \\
\text { started }\end{array}$ & $108(73.5)$ & $18(72.0)$ & $17(73.9)$ \\
\hline $\begin{array}{l}\text { Radical treatment } \\
\text { not started }\end{array}$ & $39(26.5)$ & $7(28.0)$ & $6(26.1)$ \\
\hline $\begin{array}{l}\text { Unfit for radical } \\
\text { treatment } \\
\text { Other staging } \\
\text { investigation(s) } \\
\text { demonstrated } \\
\text { advanced disease }\end{array}$ & $\begin{array}{l}22(56.4) \\
5(12.8)\end{array}$ & $\begin{array}{l}5(71.4) \\
1(14.3)\end{array}$ & $\begin{array}{l}1(1.7) \\
4(66.6)\end{array}$ \\
\hline $\begin{array}{l}\text { Patient choice } \\
\text { Unknown }\end{array}$ & $\begin{array}{l}3(7.7) \\
6(15.4)\end{array}$ & $\begin{array}{l}0(0) \\
1(14.3)\end{array}$ & $\begin{array}{l}1(1.7) \\
0(0)\end{array}$ \\
\hline $\begin{array}{l}\text { Radical treatment } \\
\text { completed }\end{array}$ & $96(88.9)$ & $18(100)$ & $14(82.4)$ \\
\hline $\begin{array}{l}\text { Radical treatment } \\
\text { not completed } \\
\text { Disease progression } \\
\text { during neoadjuvant } \\
\text { treatment }\end{array}$ & $\begin{array}{l}13(12.0) \\
8(61.5)\end{array}$ & $\begin{array}{l}0(0) \\
0(0)\end{array}$ & $\begin{array}{l}3(17.6) \\
1(33.3)\end{array}$ \\
\hline $\begin{array}{l}\text { Toxicity during } \\
\text { neoadjuvant } \\
\text { treatment } \\
\text { Inoperability at } \\
\text { planned surgery }\end{array}$ & $4(30.8)$ & $\begin{array}{l}0(0) \\
0(0)\end{array}$ & $2(66.7)$ \\
\hline \multicolumn{4}{|c|}{$\begin{array}{l}\text { Abbreviations: } \mathrm{CTS}=\text { computerised tomography; } \mathrm{PET}-\mathrm{CT}=\text { fluorodeoxyglucose positron } \\
\text { emission tomography-computed tomography. }\end{array}$} \\
\hline
\end{tabular}

between the groups because of small patient numbers and the need for a longer follow-up period, and it is therefore suggested that future studies might address this issue. Last, although 22 of 23 patients in whom PET-CT prompted further investigations underwent biopsy, histological confirmation was not undertaken where PET-CT showed metastatic disease and the CTS did not. It is assumed, therefore, rather than certain, that the PET-CT findings were accurate and resulted in a correct change in MDT 
recommendation. Whereas this approach may be practiced by many centres, there is emerging evidence, although limited, that biopsy of metastases identified by PET-CT may be required and this warrants further investigation (Han et al, 2012; Bingham et al, 2013).

This study has demonstrated the importance of PET-CT in achieving more accurate selection of patients for radical treatment of oesophageal cancer. Avoiding radical treatment in those with previously undetected advanced disease offers direct benefits for patients by preventing the detrimental effects of these therapies on health-related quality of life (Avery et al, 2007; Abate et al, 2010), and also has financial implications for hospital trusts. This is exemplified by the recently published SCOPE-1 trial, which assessed the impact of the addition of cetuximab to definitive chemoradiotherapy in the treatment of oesophageal cancer (Crosby et al, 2013). In this study, $86 \%$ of patients were staged with PET-CT, which may explain why 2 -year survival rates (56\%) were higher than anticipated (35\%). It is therefore recommended that national guidelines are followed by all UK cancer centres, such that patients considered for radical treatment of oesophageal and oesophago-gastric cancer always undergo PET-CT. Currently, such patients undergo CTS and PET-CT separately because the quality of the CT component of PET-CT is inferior to CTS alone. Future research and investment should address this issue and aim to amalgamate these investigations, meaning that patients need to undergo only one test. This will reduce hospital attendances, streamline the staging process, and provide patients with prompt access to the correct treatments, whether radical or palliative in nature.

\section{CONFLICT OF INTEREST}

The authors declare no conflict of interest.

\section{REFERENCES}

Abate E, DeMester SR, Zehetner J, Oezcelik A, Avazi S, Costales J, Banki F, Lipham JC, Hagen JA, DeMeester TR (2010) Recurrence after esophagectomy for adenocarcinomas: defining optimal follow-up intervals and testing. J Am Coll Surg 210(4): 428-435.

Allum WH, Blazeby JM, Griffin SM, Cunningham D, Jankowski JA, Wong R. Association of Upper Gastrointestinal Surgeons of Great Britain and Ireland, the British Society of Gastroenterology and the British Association of Surgical Oncology (2011) Guidelines for the management of oesophageal and gastric cancer. Gut 60(11): 1449-1472.

Avery KN, Metcalfe C, Barham CP, Alderson D, Falk SJ, Blazeby JM (2007) Quality of life during potentially curative treatment for locally advanced oesophageal cancer. Br J Surg 94(11): 1369-1376.

Bingham BA, Hatef DA, Chevez-Barrios P, Blackmon SH, Kim MP (2013) Increased FDG activity in a dermatofibroma in esophageal cancer patient. Clin Nucl Med 38(3): e140-e142.

Brown C, Howes B, Jamieson GG, Bartholomeusz D, Zingg U, Sullivan TR, Thompson SK (2012) Accuracy of PET-CT in predicting survival in patients with esophageal cancer. World J Surg 36(5): 1089-1095.

Crosby T, Hurt CN, Falk S, Gollins S, Mukherjee S, Staffurth J, Ray R, Bashir N, Bridgewater JA, Geh JI, Cunningham D, Blazeby J, Roy R, Maughan T, Griffiths G (2013) Chemoradiotherapy with or without cetuximab in patients with oesophageal cancer (SCOPE1): a multicentre, phase 2/3 randomised trial. Lancet Oncol 14(7): 627-637.

Department of Health (2000) The NHS Cancer Plan. Department of Health Publications: London.

Gillies RS, Middleton MR, Han C, Marshall RE, Maynard ND, Bradley KM, Gleeson FV (2012) Role of positron emission tomography-computed tomography in predicting survival after neoadjuvant chemotherapy and surgery for oesophageal adenocarcinoma. Br J Surg 99(2): 239-245.

Gillies RS, Middleton MR, Maynard ND, Bradley KM, Gleeson FV (2011) Additional benefit of $18 \mathrm{~F}$-fluorodeoxyglucose integrated positron emission tomography/computed tomography in the staging of oesophageal cancer. Eur Radiol 21: 274-280.

Han D, Yu J, Zhong X, Fu Z, Mu D, Zhang B, Xu G, Yang W, Zhao S (2012) Comparison of the diagnostic value of 3-deoxy-3-18F-fluorothymidine and 18F-fluorodeoxyglucose positron emission tomography/computed tomography in the assessment of regional lymph node in thoracic esophagealsquamous cell carcinoma: a pilot study. Dis Esophagus 25(5): 416-426.

Kingsmore D, Hole D, Gillis C (2004) Why does specialist treatment of breast cancer improve survivial? The role of surgical management. $\mathrm{Br} J$ Cancer 90: $1920-1925$.

Klayton T, Li T, Yu JQ, Keller L, Cheng J, Cohen SJ, Meropol NJ, Scott W, Xu-Welliver M, Konski A (2012) The role of qualitative and quantitative analysis of F18-FDG positron emission tomography in predicting pathologic response following chemoradiotherapy in patients with esophageal carcinoma. J Gastrointest Cancer 43(4): 612-618.

Luxford K, Rainbird K (2001) Multidisciplinary care for women with breast cancer: a national demonstration program. NS W Public Health Bull 12: 277-279.

Noble F, Bailey D, SWCIS Upper Gastrointestinal Tumour Panel, Tung K, Byrne JP (2009) Impact of integrated PET/CT in the staging of oesophageal cancer-a UK population-based cohort study. Eur Radiol 64: 699-705.

National Oesophago-Gastric Cancer audit (2010) IC23090209, 1-60. The NHS Information Centre.

Salahudeen HM, Balan A, Naik K, Mirsadraee S, Scarsbrook AF (2008) Impact of the introduction of integrated PET-CT into the preoperative staging pathway of patients with potentially operable oesophageal carcinoma. Clin Radiol 63: 765-773.

Shum WY, Ding HJ, Liang JA, Yen KY, Chen SW, Kao CH (2012) Use of pretreatment metabolic tumor volumes on PET-CT to predict the survival of patients with squamous cell carcinoma of esophagus treated by curative surgery. Anticancer Res 32(9): 4163-4168.

Tan S, Kligerman S, Chen W, Lu M, Kim G, Feigenberg S, D’Souza WD, Suntharalingam M, Lu W (2013) Spatial-temporal [(18)F]FDG-PET features for predicting pathologic response of esophageal cancer to neoadjuvant chemoradiation therapy. Int J Radiat Oncol Biol Phys 85(5): 1375-1382.

The Royal College of Radiologists and the Royal College of Physicians (2012) Evidence based indications for the use of PET-CT in the United Kingdom. Available at http://www.rcr.ac.uk/docs/radiology/pdf/BFCR\%2812\%293_ PETCT.pdf. Accessed 02 June 2012.

Tripathy D (2003) Multidisciplinary care for breast cancer: barriers and solutions. Breast J 9: 60-63.

Tunis S, Whicher D (2009) The National Oncologic PET Registry: lessons learned for coverage with evidence development. J Am Coll Radiol 6(5): 360-365.

Valdagni R, Salvioni R, Nicolai N, Villa S, Bedini N, Bajetta E, Procopio G, Donegani S, Bosisio M (2005) In regard to Kagan: 'The multidisciplinary clinic'. Int J Radiat Oncol Bio Phys 61: 967-968.

Van Nes J, Van de Velde C (2005) The multidisciplinary breast cancer team: promoting better care. Ned Tijdschr Geneeskd 149: 1929-1931.

Yanagawa M, Tatsumi M, Miyata H, Morii E, Tomiyama N, Watabe T, Isohashi $\mathrm{K}$, Kato $\mathrm{H}$, Shimosegawa $\mathrm{E}$, Yamasaki M, Mori M, Doki $\mathrm{Y}$, Hatazawa J (2012) Evaluation of response to neoadjuvant chemotherapy for esophageal cancer: PET response criteria in solid tumors versus response evaluation criteria in solid tumors. J Nucl Med 53(6): 872-880.

Zhu W, Xing L, Yue J, Sun X, Sun X, Zhao H, Yu J (2012) Prognostic significance of SUV on PET/CT in patients with localised oesophagogastric junction cancer receiving neoadjuvant chemotherapy/ chemoradiation: a systematic review and meta-analysis. $\mathrm{Br} J$ Radiol 85(1017): e694-e701.

Zorbas H, Barraclough B, Rainbird K, Luxford K, Redman S (2003) Multidisciplinary care for women with early breast cancer in the Australian context: what does it mean? Med J Aust 179: 528-531.

This work is published under the standard license to publish agreement. After 12 months the work will become freely available and the license terms will switch to a Creative Commons AttributionNonCommercial-Share Alike 3.0 Unported License. 